\title{
Researches on the Influences of Common Rail Pressures on the Diesel Engine's Sabah Cycle
}

\author{
Feng Liu \\ Department of Technology, Yinjian Automobile Repair Co., Ltd., Beijng, China
}

\section{Email address:}

phoneisthefirst@163.com

\section{To cite this article:}

Feng Liu. Researches on the Influences of Common Rail Pressures on the Diesel Engine's Sabah Cycle. Advances in Applied Sciences. Vol. 3, No. 3, 2018, pp. 19-27. doi: 10.11648/j.aas.20180303.11

Received: June 2, 2018; Accepted: July 6, 2018; Published: August 8, 2018

\begin{abstract}
There are directly effects on diesel's Sabah cycle of common rail pressure, at the same time, the common rail pressure also affects the property indices: pre-expansion ratio, thermal efficiency, exergy efficiency and average valid pressure. It takes Weicai National VI diesel as an instance, describes the simplifies, basic presumptions and formulas of inner cylinder thermal process, and mainly designs and researches on the property indices of Sabah Cycle in different common rail pressure conditions, includes: the rail pressure effects towards pressure inner cylinder, combustion temperature, etc.; and takes oil consumption as the optimizing target, optimized and gained the MAP of rail pressure, the oil consumption after optimizing are satisfied with the design requirements.
\end{abstract}

Keywords: Common Rail Pressure, Diesel Engine, Sabah Cycle

\section{Introduction}

This thesis takes Weicai National VI as a research target, this engine succeeds the primary one's features of advance technology, excellent function, high reliability, and may relay on moving to the higher exhaust standard. As shown in table 1 is the main technical parameters $[1,2]$.

Table 1. Common Rail Diesel Engine Technical Parameters.

\begin{tabular}{ll}
\hline Emission Level & National 6 \\
\hline Model & Turbo \& Middle Cooler, Electric Control High Pressure Common Rail \\
\hline Exhaust Volume & $11.596 \mathrm{~L}$ \\
Cylinder Diameter $\times$ Piston Travel & $126 \times 155 \mathrm{~mm}$ \\
Rational Power & $245 \mathrm{~kW}$ \\
Rational Rotate Speed & $1900 \mathrm{r} / \mathrm{min}$ \\
Maximum Torque & $1600 \mathrm{~N} \cdot \mathrm{m}$ \\
Compress Ration & $17: 1$ \\
Ignite Order & $1-5-3-6-2-4$ \\
Turbo Ratio & $1.85: 1$ \\
\hline
\end{tabular}

The compositions of high pressure common rail fuel injection system mainly includes [3-5]: oil supply pump, common rail tube, high pressure oil tube, fuel injectors, electronic control unit and various sensors;

Its basic working principle is as follow: The fuel supply pump conveys the fuel to the common rail, and an oil supply method that electrically separates the generation of the injection pressure from the injection process.

The common rail system high pressure oil pump mainly uses the CP3.3N-16/18 high pressure oil pump; The mechanical part and the actuator of high pressure common rail fuel injection system use the Bosch related spare part, the fuel injector is the CRIN2 type fuel injector, The electronic control unit uses EDC7, and the common rail uses LWRN3 common 
rail.

\subsection{Basic Presumptions on the Calculations of Inner Cylinder Thermal Processes}

For the establishment of inner cylinder combustion model, a quasi-dimensional model $[1,6,7]$ has been adopted. Here is to explain: in the quasi-dimensional model, considering the non-uniformity in the cylinder, the fuel injection is divided into several small areas according to the empirical formula of non-uniform distribution of fuel air in the cylinder. Each small area is an independent one. The thermodynamic system also considers that the processes carried out in the relevant areas are all affected by the turbulent flow in the cylinder; the model is a process conceptualized by the diesel engine: fuel injection, spray crushing, mixture formation, heat release, heat transfer, and exhaust compositions.

\subsection{Basic Formulas of Inner Cylinder Thermal Processes}

Inner cylinder thermal processes in diesel engines are relatively complex, but there are always three parameters or $(\mathrm{p}, \mathrm{T}, \mathrm{v})$ that represent the state of the gas in the cylinder; the process can be linked by energy, mass conservation equations, and equations of state.

(1) Basic Formula of Energy Conservation

According to the first theory of thermodynamics, established a formula of inner cylinder energy conservation:

$$
\frac{d(m u)}{d \varphi}=-p \cdot \frac{d V_{s}}{d \varphi}+\frac{d Q_{B m}}{d \varphi}-\sum \frac{d Q_{w i}}{d \varphi}-h_{e x} \cdot \frac{d m_{e x}}{d \varphi}
$$

Among them: $m$-Inner cylinder working air quality, $\mathrm{kg}$; $u$-Internal energy of inner cylinder air; p- Inner cylinder pressure, $\mathrm{MPa} ; V_{s}$-Cylinder working volume, $\mathrm{L} ; Q_{B m}$ Heat absorption, kJ; $Q_{w i}$-Heat loss through the boundary

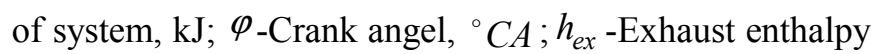
from cylinder, $\mathrm{kJ} / \mathrm{kg} ; \frac{d m_{e x}}{d \varphi}$-Exhaust flow rate from cylinder, $\mathrm{kg} /{ }^{\circ} \mathrm{CA}$

(2) Formula of Mass Conservation

The amount of change in gas mass in a diesel engine cylinder is equal to the mass of fuel injected into the cylinder, the mass of gas flowing into the cylinder, and the mass of the gas flowing out of the cylinder, the formula is as below

$$
\frac{d m}{d \varphi}=\frac{d m_{\beta}}{d \varphi}+\frac{d m_{s}}{d \varphi}-\frac{d m_{c}}{d \varphi}
$$

Among them: $m_{\beta}$-Fuel mass injected into the cylinder, kg; $m_{s}$-Air mass flow into the cylinder, $\mathrm{kg} ; m_{e}$-Air mass flow out of the cylinder, $\mathrm{kg}$

(3) Raw of Combustion and Heat Release

Utilizing Weber's combustion model as the engine cylinder heat release model for diesel engines, the empirical formulas for Weber's combustion are as below:

$$
\begin{gathered}
\frac{d x}{d \varphi}=\frac{\alpha}{\Delta \varphi_{c}} \cdot(m+1) \cdot y^{m} \cdot e^{-a \cdot y(m+1)} \\
d x=\frac{d Q_{B m}}{Q_{B m}} \\
y=\frac{\varphi-\varphi_{0}}{\Delta \varphi_{c}}
\end{gathered}
$$

Among them: $Q_{B m}$ - Heat absorption, $\mathrm{kJ} ; \varphi_{0}$-Combustion start, ${ }^{\circ} C A ; \Delta \varphi_{c}$-Combustion duration, ${ }^{\circ} C A ; m$-Combustion quality index; $\alpha$-weber parameter ( $\alpha=6.9) ; \varphi$-Crank angel,

${ }^{\circ} \mathrm{CA}$;

Exergy and Exergy Efficiency

Heat Exergy in Heat Absorption Capacity $Q_{B}$ :

$$
e_{x, Q}=Q_{B}-a_{n, Q}=\left(1-\frac{T_{0}}{T_{1 m}}\right) Q_{B}=Q_{B}-T_{0} \Delta s_{1}
$$

Average Temperature of Heat Absorption:

$$
T_{1 m}=\frac{Q_{B}}{\Delta s_{1}}
$$

Exergy Efficiency:

$$
\eta_{e_{x}}=\frac{w_{n e t}}{e_{x, Q}}
$$

Among: $e_{x, Q}$ - Heat Exergy, $\mathrm{kJ} / \mathrm{kg} ; a_{n, Q}$ - Heat Anergy, $\mathrm{kJ} / \mathrm{kg} ; T_{1 m}$ - Average Temperature of Heat Absorption, $K$; $Q_{B}$ - Cycle Heat Absorption Capacity, $\mathrm{kJ} / \mathrm{kg} ; T_{0}$ Environment Temperature, $K ; \Delta s_{1}$ - Entropy Increase during Heat Absorption Process, $\mathrm{kJ} /(\mathrm{kg} . \mathrm{K}) ; w_{\text {net }}$-Efficient Exergy (Cycle Work), $\mathrm{kJ} / \mathrm{kg}$;

Exergy Loss:

$$
i=T_{0} s_{g}=T_{0}\left(\Delta s_{2}+\Delta s_{0}\right)=T_{0}\left(-\Delta s_{1}+\frac{Q_{2}}{T_{0}}\right)=Q_{2}-a_{n, Q}=Q_{2}-T_{0} \Delta s_{1}
$$

Among them: $i$-Exergy Loss, $\mathrm{kJ} / \mathrm{kg} ; \quad s_{g}$-Entropy Generation, $k J /(k g . K) ; \Delta s_{0}$ - Environment Entropy Increase during Exothermic Process, $\mathrm{kJ} /(\mathrm{kg} . \mathrm{K}) ; Q_{2}$-Cycle Heat Release, $k J / k g ; \Delta s_{2}$-Entropy Increase during Exothermic 
Process, $\mathrm{kJ} /(\mathrm{kg} \cdot \mathrm{K})$

\section{Researches on Sabah Cycles in Different Common Rail Pressures}

The target of the exergy analysis of Sabah cycles in different rail conditions is Weicai National 6, as shown in figure 1, 2 are $\mathrm{p}-\mathrm{v}$ figure and T-s figure of Sabah cycles.

There is a comment: under different rail pressures, the highest temperatures and pressures are different, however, The ideal air inlet and outlet temperatures are the same at 1 point: the air states at 1 point and 5 point in Figures 1 and 2 do not change with the rail pressure. As shown in table 2 is sabah cycle relative parameters.

Table 2. Sabah Cycle Relative Parameters.

\begin{tabular}{lll}
\hline Sabah Cycle & $\begin{array}{l}\text { Air intake } \\
\text { temperature } \boldsymbol{T}_{\boldsymbol{a}}\end{array}$ & Air intake pressure $\boldsymbol{p}_{\boldsymbol{a}}$ \\
\hline Relative Parameters & $27^{\circ} \mathrm{C}$ & $1.85 \mathrm{bar}$ \\
\hline
\end{tabular}

Comments: Environment temperature $T_{0}$ is $-3^{\circ} \mathrm{C}$, No.- 10 Diesel Oil, External Characteristics Rational Speed

Among them, the cycle average pressure is expressed as below:

$$
\frac{p_{t}}{p_{\mathrm{a}}}=\left(\frac{\eta_{t} Q_{B}}{c_{V} T_{\mathrm{a}}}\right)\left(\frac{1}{\kappa-1}\right)\left(\frac{\varepsilon_{c}}{\varepsilon_{c}-1}\right)
$$

Compress Ratio:

$$
\mathcal{E}_{c}=17
$$

Constant Entropy index:

$$
\kappa=1.4
$$

then,

$$
\begin{gathered}
c_{V}=0.718 \mathrm{~kJ} /(\mathrm{kg} \cdot \mathrm{K}) \\
c_{p}=1.005 \mathrm{~kJ} /(\mathrm{kg} \cdot \mathrm{K})
\end{gathered}
$$

Table 3. The Maximum Cycle Pressure Corresponding to Different Target Rail Pressures.

\begin{tabular}{lllll}
\hline Sabah Cycle & I & II & III & IV \\
\hline Target Rail Pressure & $900 \mathrm{bar}$ & $1200 \mathrm{bar}$ & $1500 \mathrm{bar}$ & $1700 \mathrm{bar}$ \\
Maximum Rail pressure & $128 \mathrm{bar}$ & $140 \mathrm{bar}$ & $160 \mathrm{bar}$ & $170 \mathrm{bar}$ \\
\hline
\end{tabular}

Condition I:

$$
p_{3}=p_{4}=128 b a r
$$

constant pressure pre-expansion ratio

$$
\rho=2
$$

1-2 constant entropy process,

$$
T_{2} v_{2}{ }^{\kappa-1}=T_{\mathrm{a}} v_{\mathrm{a}}{ }^{\kappa-1}
$$

$$
T_{2}=T_{\mathrm{a}} \varepsilon_{c}{ }^{\kappa-1}
$$

thus

$$
\begin{gathered}
T_{2}=932 \mathrm{~K} \\
p_{2} v_{2}{ }^{\kappa}=p_{\mathrm{a}} v_{\mathrm{a}}{ }^{\kappa} \\
p_{2}=p_{\mathrm{a}} \varepsilon_{c}{ }^{\kappa} \\
p_{2}=97.7 \mathrm{bar}
\end{gathered}
$$

2-3 constant volume process,

$$
\frac{p_{3}}{T_{3}}=\frac{p_{2}}{T_{2}}
$$

$$
T_{3}=1221 K
$$

the highest temperature:

$$
T_{4}=\rho \times T_{3}=2 \times 1221=2442 \mathrm{~K}
$$

Intake specific volume:

$$
\frac{p_{\mathrm{a}} v_{\mathrm{a}}}{T_{\mathrm{a}}}=R_{g}
$$

$$
\begin{aligned}
& v_{2}=v_{3}=\frac{v_{\mathrm{a}}}{\varepsilon_{c}}=0.0274 \mathrm{~m}^{3} / \mathrm{kg} \\
& v_{4}=\rho \times v_{3}=0.0548 \mathrm{~m}^{3} / \mathrm{kg}
\end{aligned}
$$

$$
v_{\mathrm{a}}=v_{5}=\frac{287 \times 300}{1.85 \times 10^{5}}=0.465 \mathrm{~m}^{3} / \mathrm{kg}
$$

4-5 constant entropy process,

$$
\begin{gathered}
T_{5} v_{5}{ }^{\kappa-1}=T_{4} v_{4}{ }^{\kappa-1} \\
T_{5}=1038 \mathrm{~K}
\end{gathered}
$$

Cycle heat absorption $\boldsymbol{Q}_{\boldsymbol{B}}$

$$
\begin{gathered}
Q_{23}=c_{V}\left(T_{3}-T_{2}\right)=0.718(1221-932)=207.5 \mathrm{~kJ} / \mathrm{kg} \\
Q_{34}=c_{p}\left(T_{4}-T_{3}\right)=1.005(2442-1221)=1227 \mathrm{~kJ} / \mathrm{kg} \\
Q_{B}=Q_{23}+Q_{34}=207.5+1227=1434.5 \mathrm{~kJ} / \mathrm{kg}
\end{gathered}
$$

Cycle heat release:

$$
Q_{2}=c_{V}\left(T_{5}-T_{1}\right)=0.718(1038-300)=530 \mathrm{~kJ} / \mathrm{kg}
$$

Cycle thermal efficiency:

$\eta_{t}=\frac{w_{\text {net }}}{Q_{B}}=\frac{Q_{B}-Q_{2}}{Q_{B}}=\frac{1434.5-530}{1434.5}=\frac{904.5}{1434.5}=63.05 \%$ 
Cycle average efficient pressure: through formula (10),

$$
p_{5}=6.4 b a r
$$

$$
p_{t}=20.6 b a r
$$

Entropy Increase during Heat Absorption Process:

Irreversible constant volume process 5-1,

$$
\begin{aligned}
& \frac{p_{5}}{T_{5}}=\frac{p_{\mathrm{a}}}{T_{\mathrm{a}}} \\
& \Delta s_{24}=c_{p} \ln \frac{T_{4}}{T_{2}}-R_{g} \ln \frac{p_{4}}{p_{2}}=1.005 \ln \left(\frac{2442}{932}\right)-0.287 \ln \left(\frac{128}{97.7}\right)=0.891 \mathrm{~kJ} /(\mathrm{kg} \cdot \mathrm{K})
\end{aligned}
$$

Heat Anergy in Heat Absorption Capacity:

$$
a_{n, Q}=T_{0} \Delta s_{24}=270 \times 0.891=240.6 \mathrm{~kJ} / \mathrm{kg}
$$

Heat Exergy in Heat Absorption Capacity:

$$
e_{x, Q}=Q_{B}-a_{n, Q}=1434.5-240.6=1194 \mathrm{~kJ} / \mathrm{kg}
$$

Average Temperature of Heat Absorption:

$$
T_{1 m}=\frac{Q_{B}}{\Delta s_{24}}=\frac{1434.5}{0.891}=1610 \mathrm{~K}
$$

Exergy Efficiency:

$$
\boldsymbol{\eta}_{e_{x}}=\frac{\boldsymbol{w}_{\text {net }}}{\boldsymbol{e}_{x, \boldsymbol{Q}}}=\frac{904.5}{1194}=\mathbf{7 5 . 7 5 \%}
$$

Exergy Loss:

$$
i=T_{0} s_{g}=Q_{2}-a_{n, Q}=530-240.6=289.4 \mathrm{~kJ} / \mathrm{kg}
$$

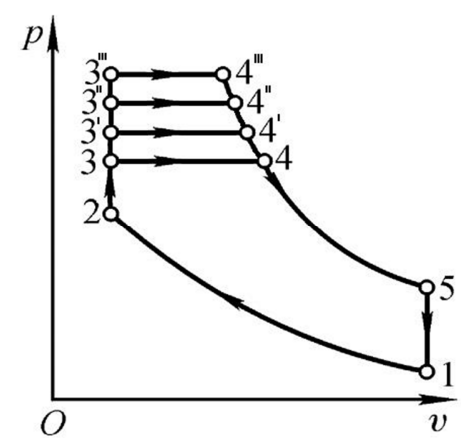

Figure 1. Sabah Cycles p-v chart.

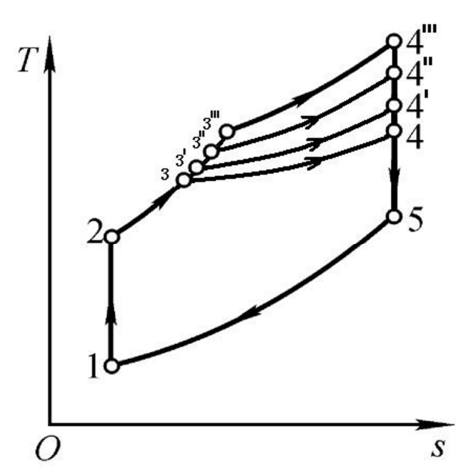

Figure 2. Sabah Cycles T-s chart.
Condition II:

$$
p_{3^{\prime}}=p_{4^{\prime}}=140 \mathrm{bar}
$$

The 1, 2, 5 points ideal air states are as the same as the results of condition I: The change of rail pressure in theoretical research content or experimental research content only involves and affects the heating process in the cylinder thermodynamic cycle, and doesn't involve any change in the exhaust system $[8,9]$, below are the same.

4'-5 constant entropy process,

$$
p_{4^{\prime}} v_{4^{\prime}}{ }^{\kappa}=p_{5} v_{5}{ }^{\kappa}
$$

$$
\begin{aligned}
& v_{4^{\prime}}=\sqrt[k]{\frac{p_{5}}{p_{4^{\prime}}}} v_{5}=0.0513 \mathrm{~m}^{3} / \mathrm{kg} \\
& v_{3^{\prime}}=v_{2}=\frac{v_{\mathrm{a}}}{\varepsilon_{c}}=0.0274 \mathrm{~m}^{3} / \mathrm{kg} \\
& v_{3^{\prime}}=v_{2}=\frac{v_{\mathrm{a}}}{\varepsilon_{c}}=0.0274 \mathrm{~m}^{3} / \mathrm{kg}
\end{aligned}
$$

2-3' constant volume process,

$$
\begin{aligned}
& \frac{p_{3^{\prime}}}{T_{3^{\prime}}}=\frac{p_{2}}{T_{2}} \\
& T_{3^{\prime}}=1335.5 \mathrm{~K}
\end{aligned}
$$

3'-4' constant pressure process,

$$
T_{4^{\prime}}=\rho \times T_{3^{\prime}}=2497 \mathrm{~K}
$$

Thus,

$$
\begin{gathered}
Q_{B}{ }^{\prime}{ }_{23^{\prime}}=c_{V}\left(T_{3^{\prime}}-T_{2}\right)=0.718(1335.5-932)=290 \mathrm{~kJ} / \mathrm{kg} \\
Q_{B}{ }^{\prime}{ }_{3^{\prime} 4^{\prime}}=c_{p}\left(T_{4^{\prime}}-T_{3^{\prime}}\right)=1.005(2497-1335.5)=1167 \mathrm{~kJ} / \mathrm{kg} \\
Q_{B}{ }^{\prime}=Q_{B}{ }^{\prime}{ }_{23^{\prime}}+Q_{B}{ }^{\prime}{ }_{3^{\prime} 4^{\prime}}=290+1167=1457 \mathrm{~kJ} / \mathrm{kg}
\end{gathered}
$$

Cycle thermal efficiency:

$$
\eta_{t}{ }^{\prime}=\frac{w_{\text {net }}{ }^{\prime}}{Q_{B}{ }^{\prime}}=\frac{Q_{B}{ }^{\prime}-Q_{2}}{Q_{B}{ }^{\prime}}=\frac{1457-530}{1457}=\frac{927}{1457}=63.62 \%
$$


Cycle average efficient pressure: through formula (10),

Entropy Increase during Heat Absorption Process:

$$
\begin{aligned}
p_{t}{ }^{\prime}=21.1 \mathrm{bar} \\
\Delta s_{24^{\prime}}=c_{p} \ln \frac{T_{4^{\prime}}}{T_{2}}-R_{g} \ln \frac{p_{4^{\prime}}}{p_{2}}=1.005 \ln \left(\frac{2497}{932}\right)-0.287 \ln \left(\frac{140}{97.7}\right)=0.887 \mathrm{~kJ} /(\mathrm{kg} \cdot \mathrm{K})
\end{aligned}
$$

Heat Anergy in Heat Absorption Capacity:

$$
a_{n, Q}{ }^{\prime}=T_{0} \Delta s_{24^{\prime}}=270 \times 0.887=239.5 \mathrm{~kJ} / \mathrm{kg}
$$

Heat Exergy in Heat Absorption Capacity:

$$
e_{x, Q}{ }^{\prime}=Q_{B}{ }^{\prime}-a_{n, Q}{ }^{\prime}=1457-239.5=1218 \mathrm{~kJ} / \mathrm{kg}
$$

Average Temperature of Heat Absorption:

$$
T_{1 m}{ }^{\prime}=\frac{Q_{B}{ }^{\prime}}{\Delta s_{24^{\prime}}}=\frac{1457}{0.887}=1643 \mathrm{~K}
$$

Exergy Efficiency:

$$
\eta_{e_{x}}{ }^{\prime}=\frac{w_{\text {net }}{ }^{\prime}}{e_{x, Q^{\prime}}}=\frac{927}{1218}=76.11 \%
$$

Exergy Loss:

$$
i^{\prime}=T_{0} s_{g}{ }^{\prime}=Q_{2}-a_{n, Q}{ }^{\prime}=530-239.5=290.5 \mathrm{~kJ} / \mathrm{kg}
$$

Condition III:

$$
p_{3^{\prime \prime}}=p_{4^{\prime \prime}}=160 \mathrm{bar}
$$

The 1, 2, 5 points ideal air states are as the same as the results of condition I,

4 "-5 constant entropy process,

$$
\begin{gathered}
Q_{B}{ }^{\prime \prime}{ }^{\prime \prime 4}=c_{p}\left(T_{4 "}-T_{3 "}\right)=1.005(2594-1526)=1073 \mathrm{~kJ} / \mathrm{kg} \\
Q_{B}{ }^{\prime \prime}=Q_{B}{ }^{\prime \prime}{ }^{23}+Q_{B}{ }^{\prime \prime}{ }^{\prime \prime} 4^{\prime \prime}=426+1073=1499 \mathrm{~kJ} / \mathrm{kg}
\end{gathered}
$$

Cycle thermal efficiency:

$$
\eta_{t} "=\frac{w_{\text {net }} "}{Q_{B}{ }^{\prime \prime}}=\frac{Q_{B}{ }^{\prime \prime}-Q_{2}}{Q_{B} "}=\frac{1499-530}{1499}=\frac{969}{1499}=64.64 \%
$$

Cycle average efficient pressure: through formula (10),

$$
p_{t}{ }^{\prime \prime}=22.1 b a r
$$

Entropy Increase during Heat Absorption Process:

$$
\Delta s_{24^{\prime \prime}}=c_{p} \ln \frac{T_{4^{\prime \prime}}}{T_{2}}-R_{g} \ln \frac{p_{4^{\prime \prime}}}{p_{2}}=1.005 \ln \left(\frac{2594}{932}\right)-0.287 \ln \left(\frac{160}{97.7}\right)=0.887 \mathrm{~kJ} /(\mathrm{kg} \cdot \mathrm{K})
$$

Heat Anergy in Heat Absorption Capacity:

$$
a_{n, Q} "=T_{0} \Delta s_{24 "}=270 \times 0.887=239.5 \mathrm{~kJ} / \mathrm{kg}
$$

Heat Exergy in Heat Absorption Capacity:

$$
e_{x, Q} "=Q_{B} "-a_{n, Q} "=1499-239.5=1260 \mathrm{~kJ} / \mathrm{kg}
$$


Average Temperature of Heat Absorption:

$$
T_{1 m}^{\prime \prime}=\frac{Q_{B} "}{\Delta s_{24 "}}=\frac{1499}{0.887}=1690 \mathrm{~K}
$$

Exergy Efficiency:

$$
\boldsymbol{\eta}_{e_{x}}{ }^{\prime \prime}=\frac{\boldsymbol{w}_{n e t}{ }^{\prime \prime}}{\boldsymbol{e}_{x, \boldsymbol{Q}}{ }^{\prime \prime}}=\frac{969}{1260}=76.90 \%
$$

Exergy Loss:

$$
i^{\prime \prime}=T_{0} s_{g} "=Q_{2}-a_{n, Q} "=530-239.5=290.5 \mathrm{~kJ} / \mathrm{kg}
$$

Condition IV:

$$
p_{3^{\prime \prime}}=p_{4^{\prime \prime}}=\mathbf{1 7 0} \mathrm{bar}
$$

The 1, 2, 5 points ideal air states are as the same as the results of condition I,

4 "' -5 constant entropy process,

$$
p_{4 \mathrm{~m}} v_{4 " \mathrm{~m}}{ }^{\kappa}=p_{5} v_{5}{ }^{\kappa}
$$

$$
\begin{aligned}
& Q_{B}{ }^{\prime \prime}{ }^{\prime \prime \prime} 4 \text { "' }=c_{p}\left(T_{4 " '}-T_{3 " '}\right)=1.005(2644-1622)=1027 \mathrm{~kJ} / \mathrm{kg}
\end{aligned}
$$

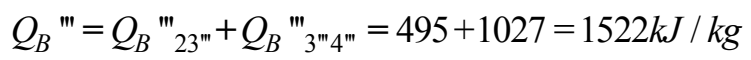

$$
\begin{aligned}
& Q_{B}{ }^{\prime \prime}{ }_{23}^{\prime \prime \prime}=c_{V}\left(T_{3 " '}-T_{2}\right)=0.718(1622-932)=495 \mathrm{~kJ} / \mathrm{kg}
\end{aligned}
$$

$$
\frac{p_{3 " '}}{T_{3 " '}}=\frac{p_{2}}{T_{2}}
$$

$$
T_{3 \mathrm{~m}}=1622 \mathrm{~K}
$$

3"'-4" constant pressure process,

$$
T_{4 " '}=\rho^{\prime \prime \prime} \times T_{3^{\prime \prime \prime}}=2644 K
$$

Thus,

Cycle thermal efficiency:

$$
\eta_{t}{ }^{\prime \prime}=\frac{w_{\text {net }}{ }^{\prime \prime}}{Q_{B}{ }^{\prime \prime}}=\frac{Q_{B}{ }^{\prime \prime}-Q_{2}}{Q_{B}{ }^{\prime \prime}}=\frac{1522-530}{1522}=\frac{992}{1522}=65.18 \%
$$

Cycle average efficient pressure: through formula (10),

$$
p_{t}{ }^{\prime \prime}=22.6 b a r
$$

Entropy Increase during Heat Absorption Process:

$$
\Delta s_{24 " '}=c_{p} \ln \frac{T_{4 " '}}{T_{2}}-R_{g} \ln \frac{p_{4 " '}}{p_{2}}=1.005 \ln \left(\frac{2644}{932}\right)-0.287 \ln \left(\frac{170}{97.7}\right)=0.889 \mathrm{~kJ} /(\mathrm{kg} \cdot \mathrm{K})
$$

Heat Anergy in Heat Absorption Capacity:

$$
a_{n, Q} " '=T_{0} \Delta s_{24 " '}=270 \times 0.889=240.0 \mathrm{~kJ} / \mathrm{kg}
$$

Heat Exergy in Heat Absorption Capacity:

$$
e_{x, Q}{ }^{\prime \prime}=Q_{B}{ }^{\prime \prime}-a_{n, Q}{ }^{\prime \prime}=1522-240.0=1282 \mathrm{~kJ} / \mathrm{kg}
$$

Average Temperature of Heat Absorption:

$$
T_{1 m}^{\prime \prime \prime}=\frac{Q_{B}{ }^{\prime \prime}}{\Delta s_{24}{ }^{\prime \prime}}=\frac{1522}{0.889}=1712 \mathrm{~K}
$$

Exergy Efficiency:

$$
\eta_{e_{x}}{ }^{\prime \prime \prime}=\frac{w_{n e t}{ }^{\prime \prime \prime}}{\boldsymbol{e}_{x, \boldsymbol{Q}}{ }^{\prime \prime \prime}}=\frac{992}{1282}=\mathbf{7 7 . 3 8 \%}
$$

Exergy Loss:

$$
i^{\prime \prime}=T_{0} s_{g}{ }^{\prime \prime}=Q_{2}-a_{n, Q}{ }^{\prime \prime}=530-240.0=290.0 \mathrm{~kJ} / \mathrm{kg}
$$

Table 4 is the contrast results among the 4 different rail pressure, the this table, it'll be able to discover that: with the rail pressure raise up, the cycle heat absorption $Q_{B}$, cycle thermal efficiency $\eta_{t}$, exergy efficiency $\eta_{e_{x}}$, cycle average efficient pressure $p_{t}$ are increased, however, the constant pressure pre-expansion ratio $\rho$ declined. 
Table 4. Results Comparison among 4 rail pressures.

\begin{tabular}{lllll}
\hline & I & II & III & IV \\
\hline$Q_{B}(\mathrm{~kJ} / \mathrm{kg})$ & 1434.5 & 1457 & 1499 & 1522 \\
$\rho$ & 2 & 1.87 & 1.70 & 1.63 \\
$\eta_{t}(\%)$ & 63.05 & 63.62 & 64.64 & 65.18 \\
$\eta_{e_{x}}(\%)$ & 75.75 & 76.11 & 76.90 & 77.38 \\
$p_{t}(\mathrm{~b} a r)$ & 20.6 & 21.1 & 22.1 & 22.6 \\
\hline
\end{tabular}

Table 5 is exergy analysis results of the Sabah cycles in different common rail pressures: with the rail pressure grows, the heat exergy in heat absorption, the average temperature of heat absorption and the exergy efficiency increase, however the exergy loss keeps in a stable range basically.

Table 5. Exergy Analysis Results of the Sabah Cycles in Different Rail Conditions.

\begin{tabular}{lllll}
\hline Condition & $\mathrm{e}_{\mathbf{x}, \mathbf{Q}}(\boldsymbol{k J} / \boldsymbol{k g})$ & $\mathrm{T}_{1 \mathrm{~m}}(\boldsymbol{K})$ & $\boldsymbol{\eta}_{\boldsymbol{e}_{\boldsymbol{x}}}(\mathbf{\%})$ & $\boldsymbol{i}(\boldsymbol{k J} / \boldsymbol{k g})$ \\
\hline I & 1194 & 1610 & 75.75 & 289.4 \\
II & 1218 & 1643 & 76.11 & 290.5 \\
III & 1260 & 1690 & 76.90 & 290.5 \\
IV & 1282 & 1712 & 77.38 & 290.0 \\
\hline
\end{tabular}

Figure 3 is the effect of rail pressure on inner cylinder

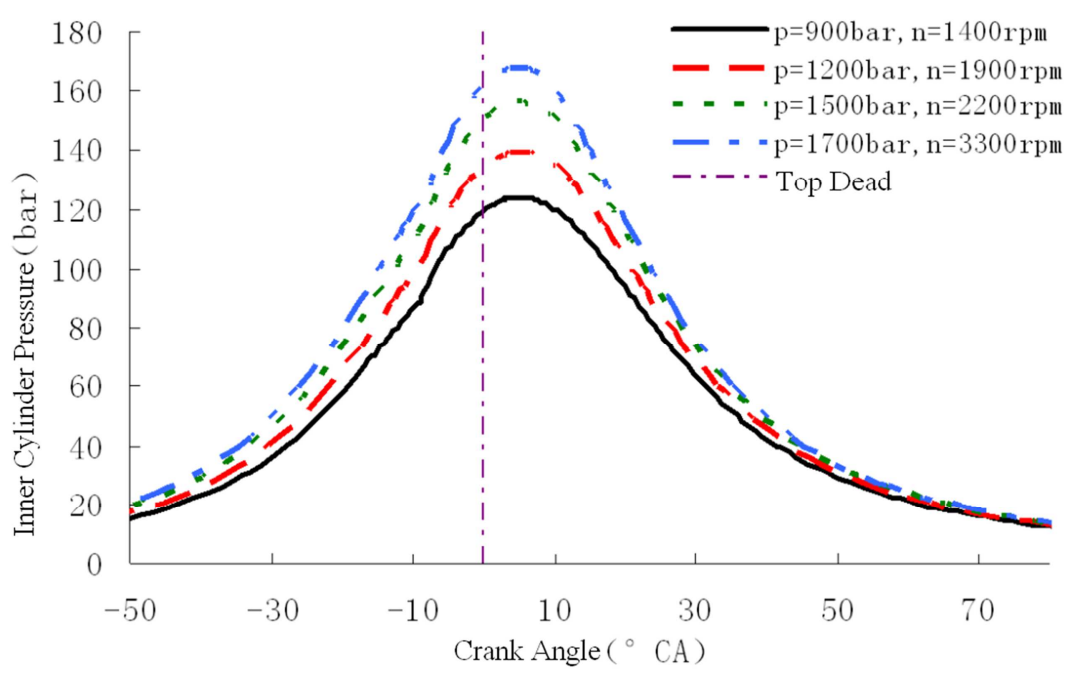

Figure 3. Effect of Rail Pressure on Inner cylinder Pressure.

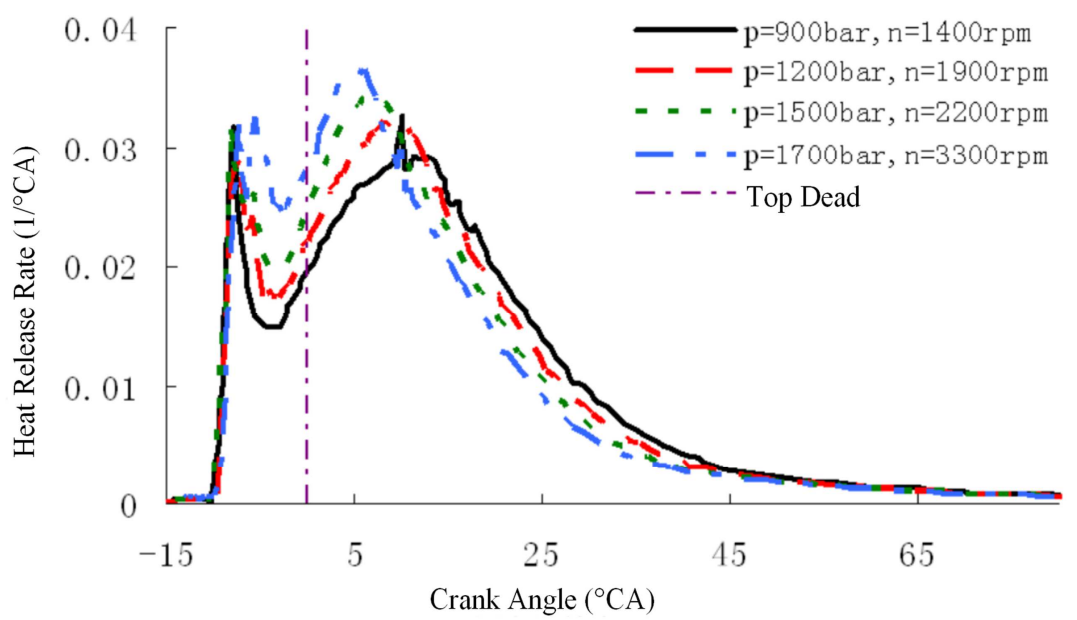

pressure. It could be analyzed that the combustion pressure, temperature, and cycle thermal efficiency of the four different target rail pressures increase with the rail pressure, the maximum explosion pressure and the combustion temperature in the cylinder increase, and the heat release rate increases at the initial stage of combustion and the peak heat release rate increases, as it shown in figure 4, the later heat release rate decreases, and the combustion time decreases.

This is mainly due to the rise of the rail pressure of the common rail, which increases the oil supply pressure of the oil supply pump and prolongs the oil supply time, resulting in an actual rail pressure [10]. When the pressure rises, the injection pressure and the injection rate increase, the injection rate and the injection pressure increase, and the injection duration of the fuel is shortened. At the same time, the formation process and the combustion process of the higher quality combustible mixture are shortened. Diffusion combustion period, these make the diesel engine cylinder combustion more similar to the constant volume combustion, enhances the diesel engine's cycle thermal efficiency, the kinetic energy of the flow in the cylinder is increased, the kinetic energy increase can improve the oil and gas mixture, thereby increasing the combustion pressure and temperature in the cylinder, as it shown in figure 5. 
Figure 4. Effect of Rail Pressure on Heat Release Rate.

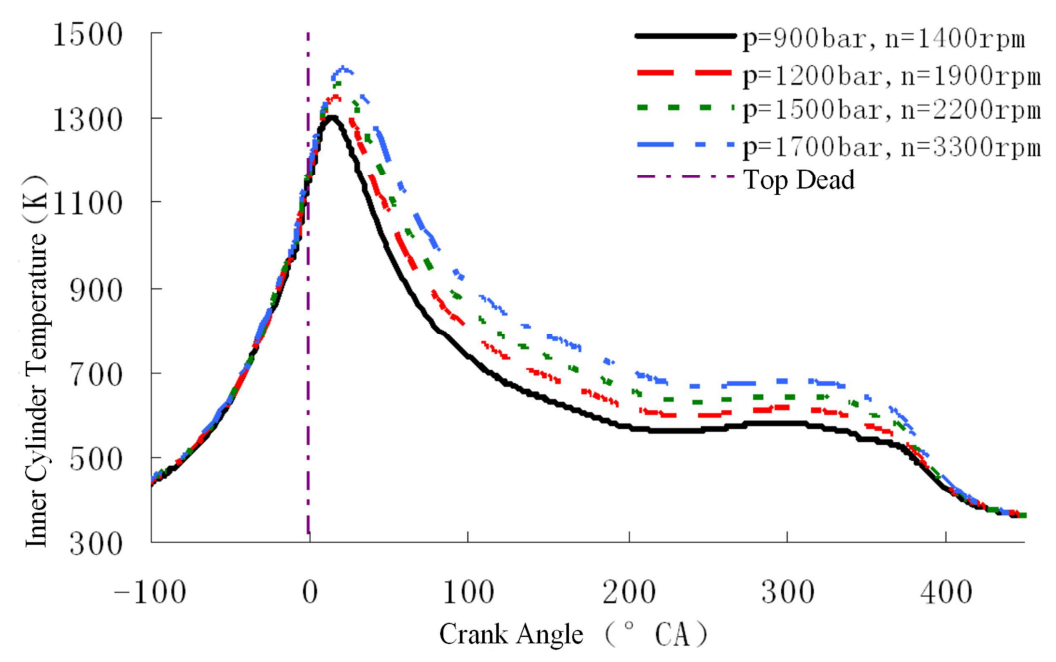

Figure 5. Effect of Rail Pressure on Inner Cylinder Temperature.

\section{Rail Pressure Optimization Design}

The horizontal coordinate of the rail pressure MAP is the diesel engine speed, the vertical coordinate is the fuel injection volume $[1,2]$. Figure 6 shows the orbital pressure MAP. It could be seen from figure 6 that the maximum rail pressure reaches about $200 \mathrm{MPa}$. Through the above research, promote common rail pressure makes the diesel engine cylinder maximum combustion pressure, maximum combustion temperature were significantly increased, so the high pressure common rail to improve diesel engine fuel consumption and exhaust smoke, improve engine thermal efficiency is valid [6-7].

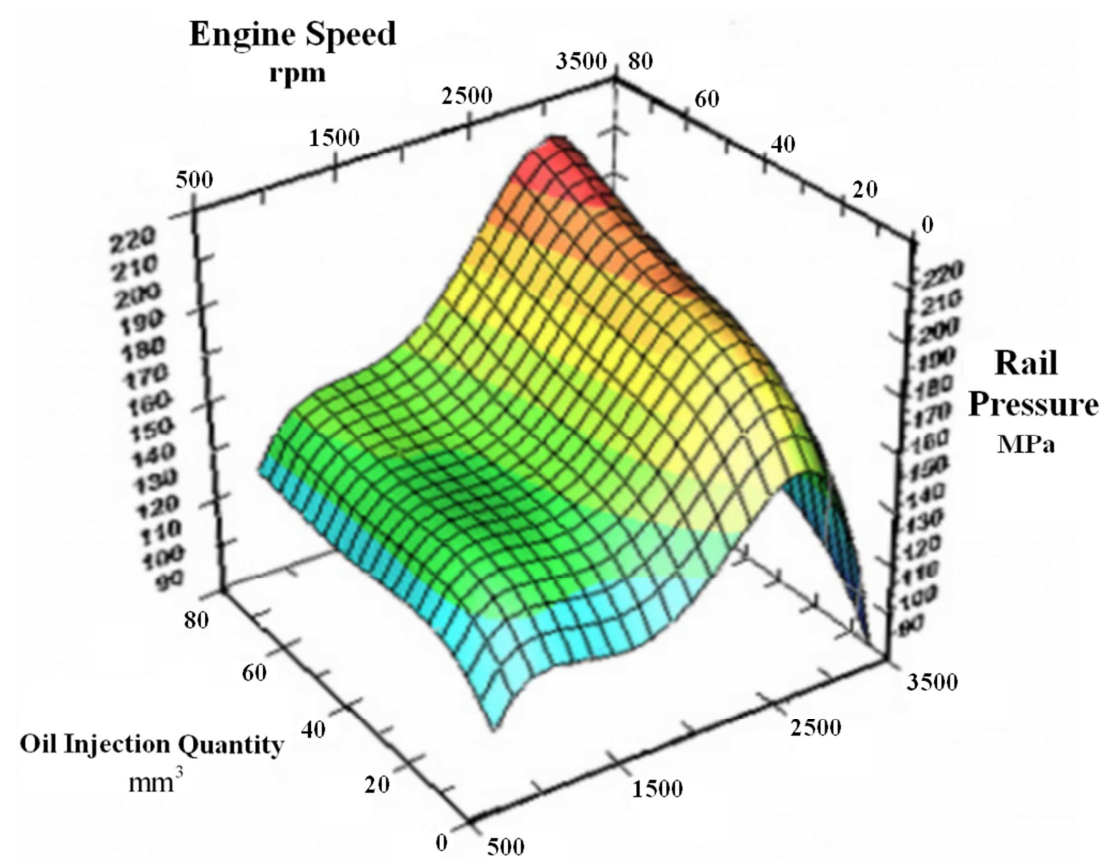

Figure 6. Rail Pressure MAP.

Through the experiment, rail pressure in common rail pressure MAP in 500-1500r/min speed significantly lower than the other speed of rail pressure, that's because at this time in order to guarantee the torque at low speed, fuel injection quantity set more, therefore, the combustion temperature is higher, is not conducive to reduce emissions, to reduce rail pressure control of combustion temperature and maximum pressure in cylinder.

Table 6 is the optimized fuel economic results, through the economic index of this table, it could be found that, the external fuel consumption rate under the maximum torque speed, rated power speed, and maximum power speed are all lower than the requirements of the design target value to meet the design requirements [10]. 
The above content selects the appropriate optimization algorithm and constraints, the fuel consumption is optimized target and the rail pressure MAP is optimized. The optimized fuel consumption rate meets the design requirements. Among them, the fuel consumption rate of the external characteristic maximum torque rotation speed, rated power rotation speed, and maximum power rotation speed is relative to the required margin of the design index: $-1.90 \%,-5.05 \%$, and $-7.93 \%$.

Table 6. Optimized external fuel economy results.

\begin{tabular}{llll}
\hline Speed Fuel Consumption & Unit & Research Result & Design Requirement \\
\hline Maximum torque speed & $g /(k W \cdot h)$ & 181.48 & $\leq 185$ \\
Rated power speed & $g /(k W \cdot h)$ & 175.65 & $\leq 185$ \\
Maximum power speed & $g /(k W \cdot h)$ & 170.32 & $\leq 185$ \\
\hline
\end{tabular}

\section{Conclusions}

This article established the basic formulas of the thermal process in the cylinder; compared with the data of cyclic heat absorption, cyclic heat efficiency, exergy efficiency, mean effective pressure, etc. of the Sabah cycle under the four different rail pressures of the common rail system, the research results show that: The rail pressure increases, the circulating heat absorption, the cycle thermal efficiency, the exergy efficiency, and the average effective pressure, etc., have increased.

For the constant pressure pre-expansion ratio, the Sabah cycle increases with the rail pressure and the constant pressure pre-expansion ratio Reduce; Introduce combustion in common cylinder system of diesel engine. With the increase of rail pressure, the heat and heat of the sabah cycle is increased with the average heat absorption temperature and exergy efficiency; Optimized the common rail oil pressure MAP, and obtained the economic optimization results to meet the design requirements.

Thus, it could be seen that the economic and energy efficiency of the thermodynamic cycle of automobile engine can be improved by adopting the necessary technical means, and the design requirements are constantly met.

\section{References}

[1] Liu Feng 2018 (Jan.) Research on the Exergy of Automobile Engine inner Cylinder Thermal Cycle J. Automobile Parts. 4145 .
[2] Liu Feng 2017 (Nov.) Research on the Exergy of Automotive Engine inner Cylinder Thermal Cycle J. Auto Time. 89-92.

[3] Liu Feng 2017 (Mar.) Research on the Sabah Cycle of Diesel with a Common Rail Injection System and Diesel Cycle $J$. Shanghai Auto. 30-34, 46.

[4] Liu Feng 2017 (Apr.) Calculation on the Sabah Cycle with a Common Rail Injection System Compared with Diesel Cycle J. Automobile Parts. 62-64.

[5] Liu Feng 2017 (May) The Influences of Common Rail Pressure on Sabah Cycle J. Automobile Parts. 63-65.

[6] F Liu. Research and Analysis on the exergy of Automotive Engine Inner Cylinder Thermal Cycle [J]. International Journal of Engineering Sciences \& Research Technology: Vol. 7 Iss. 2, Feb. $25^{\text {th }}, 18$.

[7] F Liu. Analysis on the exergy of Automobile Engine Inner Cylinder Thermodynamic Cycle [J]. Global Journal of Advanced Engineering Technologies \& Sciences: 5 (2), Feb. $28^{\text {th }}, 18$.

[8] Liu Feng 2017 (Feb.) The Influences of Diesel's Common Rail Pressure on Sabah Cycle J. Auto Time. 83-85.

[9] Liu Feng 2017 (Mar.) Researches on the Contrasts between Sabah Cycle with a Common Rail Injection System and Diesel Cycle J. Auto Industry Research. 57-62.

[10] Liu Feng 2017 (Aug.) The Influences of Diesel's Common Rail Pressure on Sabah Cycle J. Auto Industry Research. 5762. 